\title{
The Hydroxyl Group-Solvent and Carbonyl Group-Solvent Specific Interactions for Some Selected Solutes Including Positional Isomers in Acetonitrile/Water Mixed Solvents Monitored by HPLC
}

\author{
Won Jo Cheong, ${ }^{\star}$ Young Ik Keum, and Joung Ho Ko \\ Department of Chemistry and Center for Adwanced Bioseparation Technologv and Institute of Industrial Biotechnologv, \\ Inha Universin, Incheon 102-751. Korea \\ Received August 23, 2001
}

\begin{abstract}
We have evaluated the specific hydroxyl group-solvent and carbonyl group-solvent interactions by using an Alltima $C_{18}$ stationary phase and by measuring the retention data of carefully selected solutes in $60 / 40.70 / 30$, and $80 / 20(\% / \%)$ acetonitrile/water eluents at $25,30.35,40.45$, and $50{ }^{\circ} \mathrm{C}$. The selected solutes are phenol. acetophenone. alkylbenznes(benzene to hexylbenznene), 4 positional isomers of phenylbutanol, 5-phenyl-1pentanol. 3 positional isomers of alkylarylketone derived from butylbenzene. and 1-phenyl-2-hexanone. The magnitudes of hydroxyl group-acetonitrile/water specific interaction enthalpies are larger than those of carbonyl group-acetonitrile/water specific interaction enthalpies in general while the magnitudes of carbonyl group-methanol/water specific interaction enthalpies are larger than those of hydroxyl group-methanol/water specific interactions. We observed clear discrepancies in functional group-solvent specific interaction among positional isomers. The variation trends of solute transfer enthalpies and entropies with mobile phase composition in the acetonitrile/water system are much different from those in the methanol/water system. The well-known pocket formation of acetonitrile in aqueous acetonitrile nixtures has proven to be useful to explain such phenomena.
\end{abstract}

Keywords : Carbonỵl group. Hỵdroxyl group. Specific interaction. Aqueous acetonitrile. Positional isomers.

\section{Introduction}

The chromatographic enthalpies and entropies for the solute transfer from the mobile to the stationary phase can be obtained by measuring retention data over a wide range of temperature ${ }^{1.11^{2}}$ and the specific solute functional group-mobile phase interaction can be derived from such thermodynamic data. ${ }^{13.17}$ In our previous studies. we measured the specific hydroxyl group-solvent and carbonyl group-solvent interaction enthalpies and entropies of phenol and acetophenone in aqueous methanol mixtures using the squalane-impregnated $\mathrm{C}_{18}$ stationary phase. ${ }^{13}$ the specific functional group-solvent interaction enthalpies and entropies of phenol. benzylalcohol. phenenthylalcohol acetophenone. and benzylacetone in aqueous acetonitrile mixtures using the squalane-impregnated $\mathrm{C}_{18}$ stationary phase. ${ }^{16}$ and the specific functional group-solvent interaction enthalpies and entropies of 4 positional isomers of phenylbutanol. 5-phenyl-1-pentanol. 3 positional isomers of alkylary lketone derived from butylbenzene. and 1-phenyl2-hexanone in aqueous methanol mixtures using the Altima $\mathrm{C}_{1 \delta}$ stationary phase. ${ }^{17}$ We observed that accessibility of solvent molecules to the solute functional group was a crucial factor for determining the magnitude of specific solutesolvent interaction. ${ }^{13.16}$ In the later study ${ }^{17}$ where a Alltima $\mathrm{C}_{1 \delta}$ stationary phase was used. we observed that the carbonyl group-methanol/water interaction is stronger than the hydroxyl group-methanol/water interaction and that there exist clear discrepancies in functional group-solvent interaction among positional isomers
In this study, we have measured the hydroxyl group-solvent and carbonyl group-solvent specific interactions in acetonitrile/water mixtures using the Alltima $\mathrm{C}_{18}$ stationary phase and analyzed the data and compared the results with those in methanol/water mixtures.

\section{Experimental Section}

Acetonitrile and water were of HPLC grade and purchased from Fisher (Pittsburgh. USA) and used without further purification. The selected solutes (benzene, toluene, ethylbenzene. propylbenzene butylbenzene. pentylbenzene. hexylbenzene. phenol. 1-phenyl-1-butanol, 1-phenyl-2-butanol, 4phenyl-2-butanol. 4-phenyl-1-butanol. 5-phenyl-1-pentanol. acetophenone butyrophenone. 1-phenyl-2-butanone benzylacetone. and 1-phenyl-2-hexanone) were purchased from Aldrich (Milwaukee. IL. USA) and used without purification.

The experimental details were basically the same as those in the previous reports. ${ }^{1+}$ We used a home-made Alltima (Alltech. Deerfield. IL. USA) $\mathrm{C}_{18}$ column $(4.6 \times 250 \mathrm{~mm})$. The amount of stationary phase was carefully determined by measuring the weight of stationary phase used for the slurry and the weight of residual stationary phase left in the slurry reservoir and the transfer tubing after packing. ${ }^{17}$ The effective stationary phase volume and the phase ratio were determined from the weight of the stationary phase in the column and the carbon load $(16 \%){ }^{17}$ The determined phase ratio could include some error. but such error will cause a 
consistent systematic deviation and will not affect trends of variation of thermodynamic properties. The mobile phase used were acetonitrile/water mixtures (60/40.70/30. 80/20 $\mathrm{v} / \mathrm{\%} \%$ ) and the flow rate was fixed at $1 \mathrm{~mL} / \mathrm{min}$. The long retention of large alkylbenzenes forced us to exanine in such a narrow range of mobile phase composition. The solute retention data were collected at $25,30.35 .40 .45$. and $50^{\circ} \mathrm{C} . \mathrm{KNO}_{3}$ was used as the void volume marker. Three independent measurements on different days were made to calculate the themodynanic properties.

In order to estimate retention data of a hypothetical nonpolar solute whose intrinsic volume is the same as that of its polar counterpart, we measured retention data of two alkylbenzenes under condition where the intrinsic volume of the polar solute lies between those of the alhylbenzens. The capacity factor of the hypothetical nonpolar solute was calculated based on the retention data of the two alkylbenzenes under assumption that $\ln k^{\prime}$ is linear with intrinsic molar volunie.

The thermodynamic relationship between the capacity factor $(k)$ and temperature (T) was used to obtain solute transfer enthalpies and entropies and is as follows ${ }^{1-11)}$.

$$
\ln k^{\prime}=-\Delta H^{\circ} /(\mathrm{RT})+\Delta S^{\circ} / R+\ln \Phi
$$

where $\Delta H^{\circ}$ and $\Delta S^{\circ}$ are the standard enthalpy and entropy for the solute transfer from the mobile phase to the stationary phase, respectively, $\Phi$. the phase ratio, and $R$, the gas constant. We can conpute $\Delta H^{\circ}$ from the slope. and $\Delta S^{\circ}$ from the intercept.

When we consider a pair of nompolar (A) and polar (B) solutes which are of the same size and shape except for a polar functional group. the functional group-mobile phase specific interaction enthalpy and entropy equal to the differential solute transfer enthalpy $\left(\Delta H^{\nu}\right)$ and entropy $\left(\Delta 5^{\circ}\right)$ between the two solutes ${ }^{13}$ if the stationary phase is a real bulk nonpolar phase.

$$
\begin{aligned}
\Delta \Delta H^{\mathrm{D}} & =\Delta H^{\circ}{ }_{\mathrm{A}}-\Delta H^{\circ}{ }_{\mathrm{B}} \\
\Delta \Delta S^{\circ} & =\Delta S^{\circ}{ }_{\mathrm{A}}-\Delta S_{\mathrm{B}}^{\circ}
\end{aligned}
$$

\section{Results and Discussion}

The measured solute transfer enthalpies and entropies times mean temperature $\left(308.15^{\circ} \mathrm{K}\right)$ together with the Gibbs free energieis of solute transfer from the mobile to the stationary phase for all the solutes are summarized in Table 1. Standard deviations for three replicate measurements of thermodynamic properties $\left(\Delta H^{\circ},-T \Delta S^{\circ}\right)$ are less than $300 \mathrm{~J} /$ mol for the worst case. The variation trends of solute transfer enthalpies and entropies times temperature $\left(308.15^{\circ} \mathrm{K}\right.$ ) obtained in the $\mathrm{MeCN}$ (acetonitrile)/water mixed solvents for alcohols and ketones are shown in Figures 1, 2 (enthalpies) and 3,4 (entropies), respectively. in comparison with those obtained in the $\mathrm{MeOH}$ (methanol)/water mixed solvents.

We note that the solute transfer from the mobile to the stationary phase is enthalpically favorable (-sign) and entropically unfavorable (-sign) in general and that the enthalpic contribution $\left(\Delta H^{\circ}\right)$ is predominate compared to the entropic contribution $\left(-T \Delta 5^{\circ}\right)$ as we had also observed in the previous studies. 14.15 .17

Comparison of magnitudes of $\Delta H^{0}$ between alcohols and ketones. The absolute magnitude of solute transfer

\begin{tabular}{|c|c|c|c|c|c|c|c|c|c|}
\hline \multirow{3}{*}{ Solute } & \multicolumn{9}{|c|}{ Mobile phase (MeCN\%) } \\
\hline & \multicolumn{3}{|c|}{60} & \multicolumn{3}{|c|}{70} & \multicolumn{3}{|c|}{80} \\
\hline & $\Delta G^{\circ}$ & $\Delta H^{\circ}$ & $-T \Delta S^{\circ}$ & $\Delta G^{\circ}$ & $\Delta H^{\circ}$ & $-T \Delta S^{\circ}$ & $\Delta G^{\circ}$ & $\Delta H^{\circ}$ & $-T \Delta S^{\mathrm{v}}$ \\
\hline Plhenol & -2800 & -8200 & 5400 & -1900 & -7900 & 6000 & -700 & -5700 & 5000 \\
\hline 1-phenyl-1-butanol & -5200 & -5900 & 700 & -3900 & -6200 & 2300 & -2800 & -5500 & 2700 \\
\hline 1-phenyl-2-butanol & -4900 & -5200 & 300 & -3700 & -5600 & 1900 & -2600 & -1900 & 2300 \\
\hline 4-phenyl-2-butanol & +400 & -5000 & 600 & -3400 & -5600 & 2200 & -2200 & -4800 & 2600 \\
\hline 4-phenyl-1-butanol & -400 & -5700 & 1300 & -3400 & -6300 & 2900 & -2300 & -5500 & 3200 \\
\hline 5-phenyl-1-pentanol & -5300 & -6200 & 900 & -4100 & -6800 & 2700 & -2900 & -6300 & 3400 \\
\hline Acetophenone & -4300 & -7100 & 2800 & -3300 & -7000 & 3700 & -2200 & -5600 & 3400 \\
\hline Butyrophenone & -6600 & -8100 & 1500 & -5200 & -8000 & 2800 & -3800 & -7100 & 3300 \\
\hline 1-phenyl-2-butanone & -5500 & -7400 & 1900 & -1200 & -7200 & 3000 & -2900 & -6000 & 3100 \\
\hline Benzylacetone & -5200 & -7300 & 2100 & -1000 & -7300 & 3300 & -2700 & -6100 & 3400 \\
\hline 1-phenyl-2-hexanone & -7600 & -8300 & 700 & -5900 & -8300 & 2400 & -1300 & -7500 & 3200 \\
\hline Benzene & -6000 & -7400 & 1400 & -4800 & -7100 & 2300 & -3500 & -5700 & 2200 \\
\hline Toluente & -7000 & -7900 & 900 & -5700 & -7600 & 1900 & -4300 & -6600 & 2300 \\
\hline Ethylbenzene & -8000 & -8300 & 300 & -6500 & -8100 & 1600 & -5000 & -7300 & 2300 \\
\hline Butylberzene & -10200 & -9900 & -300 & -8400 & -10000 & 1600 & -6700 & -9600 & 2900 \\
\hline Pentylbenzente & -11400 & -10900 & -500 & -9500 & -11200 & 1700 & -7600 & -11000 & 3400 \\
\hline Hexylbenzente & -12500 & -11900 & -600 & -10500 & -12400 & 1900 & -8400 & -12400 & 4000 \\
\hline
\end{tabular}

Table 1. Comparison of $\Delta \mathrm{G}^{\circ}$, the solute transter free energies from the $\mathrm{MeCN} / \mathrm{H}_{2} \mathrm{O}$ mobile phase to the Alltima $\mathrm{C}_{18}$ stationary phase, with

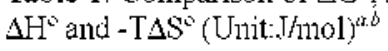

"Standard deviations for three replicate measurements of themodynamic properties $\left(\Delta H^{\circ},-T \Delta S^{\nu}\right)$ are better than $300 \mathrm{~J}$ imol for the worst case. "The Gibbs free energy of solute transfer was computed as follows: $\Delta G^{\circ}=\Delta H^{\circ}-T \Delta S^{\prime \prime}$ 


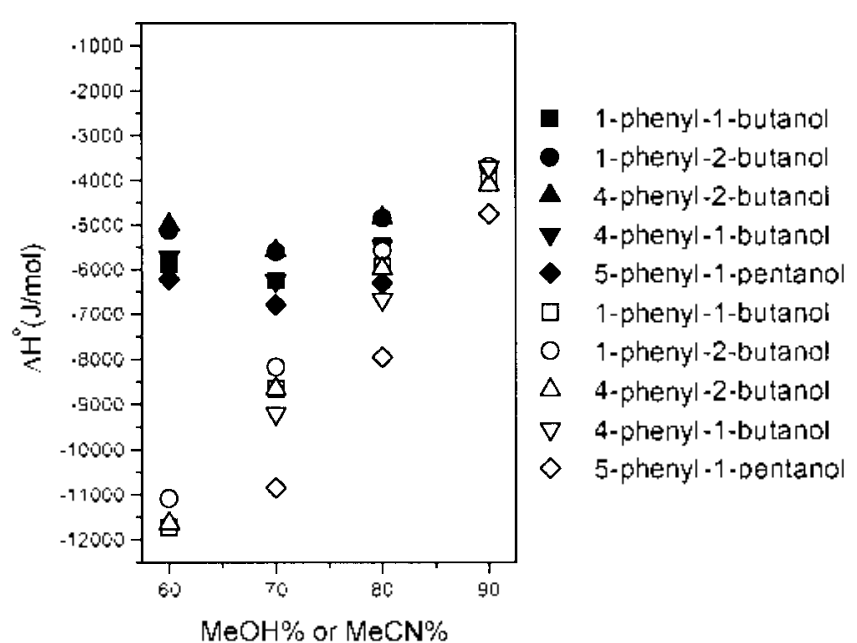

Figure 1. The solute transfer enthalpies of alcohols from the MeCN/ $\mathrm{H}_{2} \mathrm{O}$ (solid symbols) or $\mathrm{MeOH} / \mathrm{H}_{2} \mathrm{O}$ (open symbols) mobile phase to the Alltima $\mathrm{C}_{18}$ stationary phase.

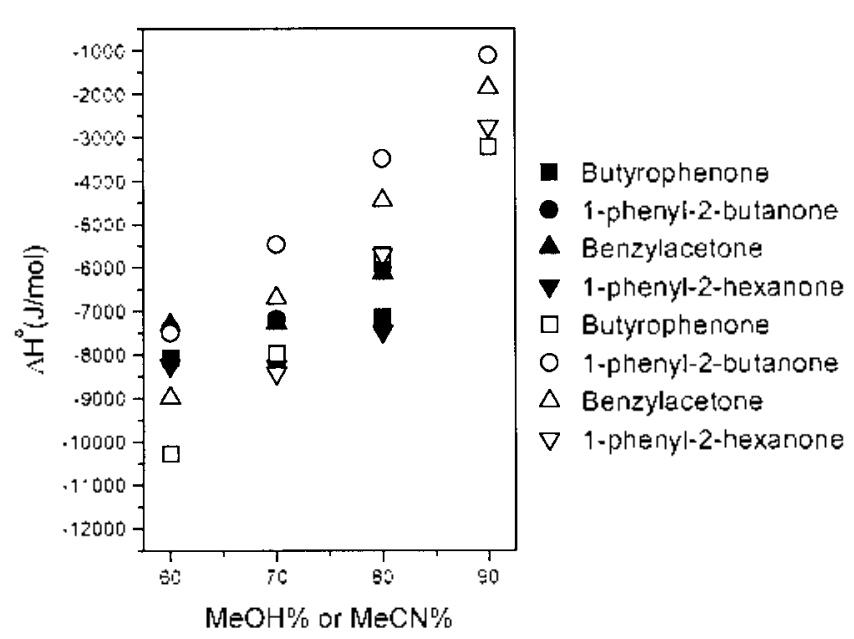

Figure 2. The solute transfer enthalpies of ketones from the $\mathrm{MeCN} / \mathrm{H}_{2} \mathrm{O}$ (solid symbols) or $\mathrm{MeOH} / \mathrm{H}_{2} \mathrm{O}$ (open symbols) mobile phase to the Alltima $\mathrm{C}_{18}$ stationary phase.

enthalpy of ketones (butyrophenone and its positional isomers) is greater than that of phenylbutanols in the $\mathrm{MeCN} /$ water solvent system (Table 1). which means that the hydroxyl group-solvent interaction is stronger than the carbonyl groupsolvent interaction in the $\mathrm{MeCN} /$ water mixed solvents. On the other hand. we had observed that the carbonyl groupsolvent interaction was greater than the hydroxyl groupsolvent interaction in the $\mathrm{MeOH} /$ water solvent system. ${ }^{17}$ Acetonitrile and ketones are able to accept but unable to donate a lydrogen bond while alcohols are able to accept and donate a hydrogen bond. Therefore. there exists hydrogen bond interaction between an alcohol and acetonitrile while there is no hydrogen bond between a ketone and acetonitrile. For such reasons, the hydroxyl group- $\mathrm{MeCN} /$ water specific interaction is stronger than the carbonyl group-MeCN/water specific interaction. We can also note clear discrepancies among positional isomers (Figures 1-4). The orders of strength of solute transfer enthalpies and

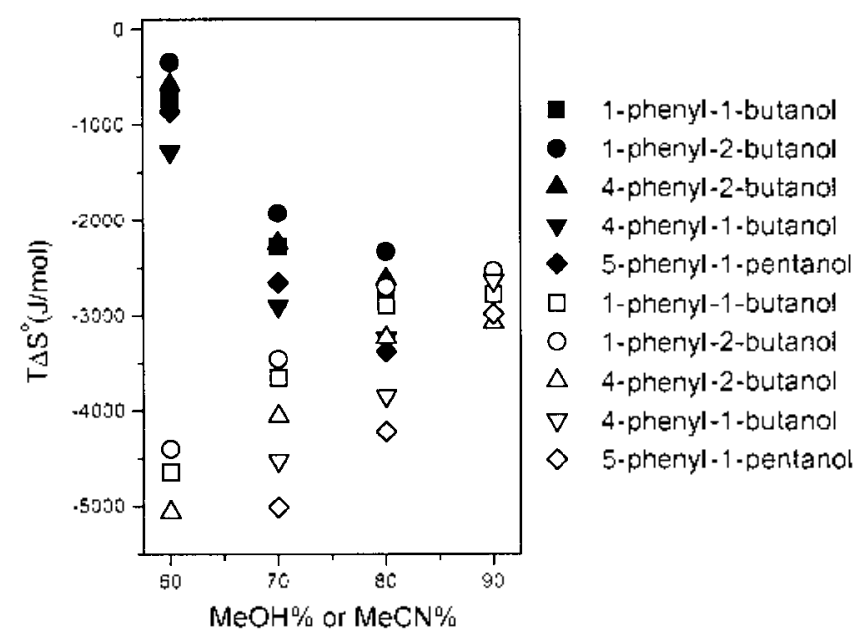

Figure 3. The solute transfer entropies of alcohols from the $\mathrm{MeCN} /$ $\mathrm{H}_{2} \mathrm{O}$ (solid symbols) or $\mathrm{MeOH} / \mathrm{H}_{2} \mathrm{O}$ (open symbols) mobile phase to the Alltima $\mathrm{C}_{18}$ stationary phase.

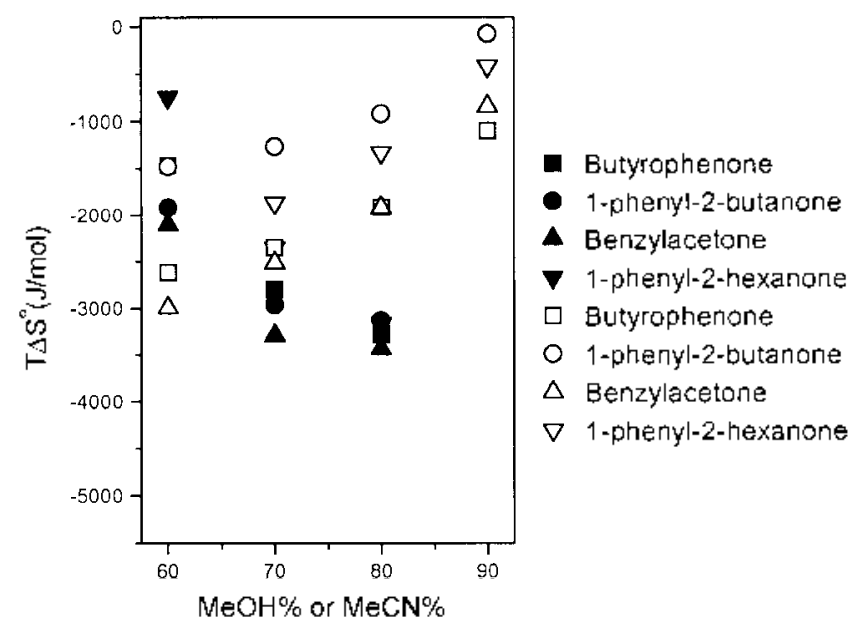

Figure 4 . The solute transfer entropies of ketones from the $\mathrm{MeCN} /$ $\mathrm{H}_{2} \mathrm{O}$ (solid symbols) or $\mathrm{MeOH} / \mathrm{H}_{2} \mathrm{O}$ (open symbols) mobile phase to the Alltima $C_{18}$ stationary phase.

entropies among positional isomers in the $\mathrm{MeCN} / \mathrm{water}$ system are in general similar to those in the $\mathrm{MeOH} /$ water system studied previously. ${ }^{17}$ Discussion on the relationships between molecular structures and strengths of functional group-solvent interactions can be found elsewhere. ${ }^{17}$

Comparison of variation trends of $\Delta H^{0}$ and $\Delta S^{0}$ between the $\mathrm{MeCN} /$ water and $\mathrm{MeOH} /$ water systems. The variation trends of solute transfer enthalpies and entropies with mobile phase composition in the $\mathrm{MeCN} /$ water system are much different from those in the $\mathrm{MeOH} /$ water system. Guillaume et $a l^{12.18-20}$ also observed remarkable differences in solute retention between the $\mathrm{MeCN} /$ water and $\mathrm{MeOH} /$ water systems. $\Delta H^{\circ}$ values follow a curved line as the composition of the organic solvent decreases in the $\mathrm{MeCN} /$ water system while a monotonous linear change in $\Delta H^{\circ}$ is observed in the $\mathrm{MeOH} /$ water system as shown in Figures I and $2 . \Delta S^{\circ}$ gets less negative in the $\mathrm{MeCN} /$ water system and more negative in the $\mathrm{MeOH} /$ water system as the composi- 
tion of organic solvent decreases (Figures 3 and 4). Getting less negative in $\Delta H^{\circ}$ and $\Delta S^{\circ}$ with increase of water content (decrease of composition of organic solvent) in the mixed solvent is a peculiar symptom of hydrophobic interaction. ${ }^{1+}$ However, it is difficult to admit hydrophobic interaction in the MeCN/water system since no symptom of hydrophobic interaction was observed in the $\mathrm{MeOH} / \mathrm{water}$ system for the same solvent composition range (Figures 1-4). Hydrophobic effect can be identified by observing a sudden shift of $\Delta H^{\circ}$ and $\Delta S^{\mathrm{D}}$ in the positive direction compared to the predicted value based on the cavity formation effect. ${ }^{17}$ If the peculiar phenomenon in the MeCN/water systent were owing to the hydrophobic effect. then such phenomenon should have been observed in the $\mathrm{MeOH} /$ water system. too. Discussion concerning the peculiar trend (getting less negative in $\Delta H^{\circ}$ and $\Delta S^{\mathrm{D}}$ with increase of water content in the mixed solvent) will be continued in the next sections.

Comparison of $\Delta H^{\circ}$ and $\Delta S^{\circ}$ in the MeCN/water system between the Alltima $\mathrm{C}_{18}$ phase and the squalane impregnated $C_{18}$ phase. We had measured $\Delta H^{\circ}$ and $\Delta S^{\circ}$ values of phenol, acetophenone. benzylacetone. and butylbenzene in the $\mathrm{MeCN} /$ water system over the composition range of 30 $70 \% \mathrm{MeCN}$ using the squalane-impregnated $\mathrm{C}_{18}$ stationary phase in one of the former studies. ${ }^{15}$ The measured thermodynamic data obtained from the Alltima $\mathrm{C}_{18}$ stationary phase in this study included the data for the solutes mentioned above. Thus we plotted the $\Delta H^{\circ}$ and $\Delta S^{\circ}$ values of the two data sets comparatively in Figures 5 and 6 . As we can see in Figures 5 and 6 , no symptom of hydrophobic interaction was observed for the data set of the squalane-inpregnated $\mathrm{C}_{18}$ stationary phase in the composition range of $30-70 \% \mathrm{MeCN}$. and the predominant cavity formation effect (getting more negative in $\Delta H^{\nu}$ with increase of water content) was observed instead. The same phenomena should be observed for the thermodynamic data obtained from the Alltina $C_{1 s}$ phase since the hydrophobic interaction is related only to the

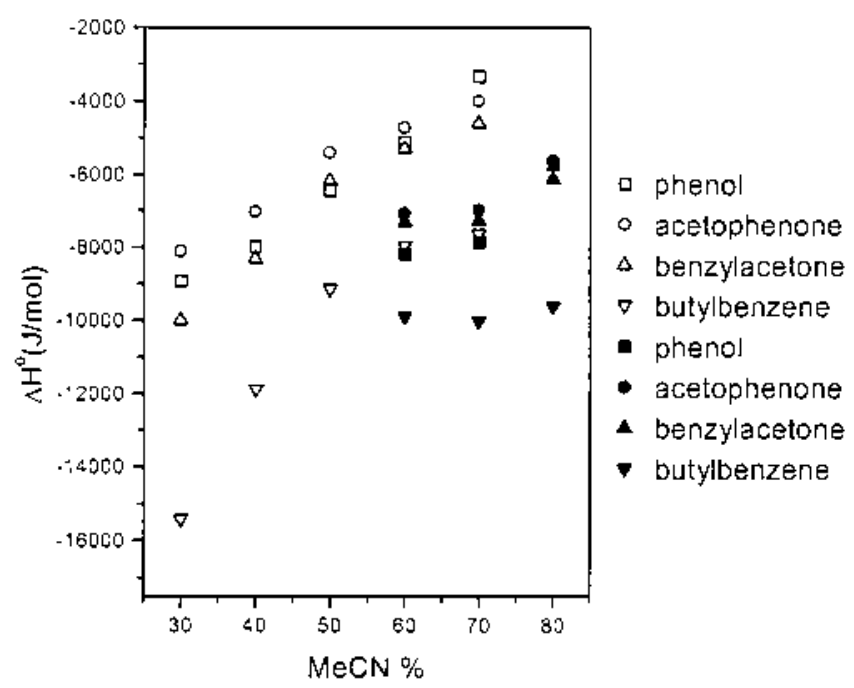

Figure 5. The solute transfer enthalpies from the $\mathrm{MeCN} / \mathrm{H}_{2} \mathrm{O}$ mobile phase to the Alltina $\mathrm{C}_{18}$ (solid symbols) or squalaneinpregnated $\mathrm{C}_{18}$ (open symbols) stationary phase.

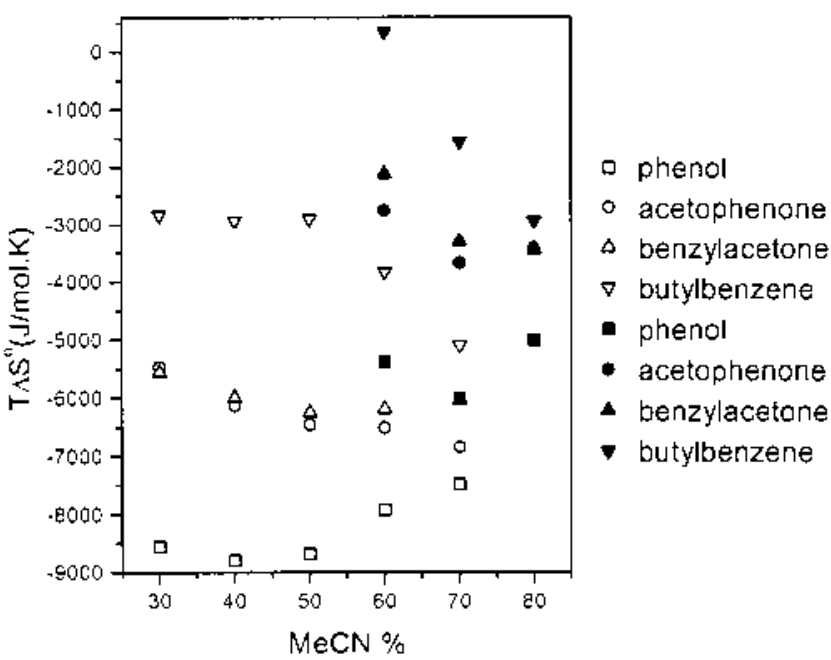

Figure 6. The solute transfer entropies from the $\mathrm{MeCN} / \mathrm{H}_{2} \mathrm{O}$ mobile phase to the Alltima $\mathrm{C}_{18}$ (solid symbols) or squalaneimpregnated $C_{18}$ (open symbols) stationary phase.

\section{mobile phase}

Adsorption of mobile phase by the Alltima $C_{18}$ phase Now that the peculiar trend (getting less negative in $\Delta H^{\mathrm{v}}$ and $\Delta S^{\mathrm{v}}$ with increase of water content in the MeCN/water solvent) is not due to hydrophobic interaction, we had better consider that the Alltima $\mathrm{C}_{18}$ phase may be unable to form a perfect bulk phase but should include adsorbed mobile phase and consequently be composed of a ligand-mobile phase mixed phase. Solutes will have higher entropy in the mixed phase than in the bulk nonpolar phase. In this mixed stationary phase region. different things will happen in comparison to situations in the real nonpolar bulk stationary phase. First, the effective stationary phase volume will be larger than the volume of collapsed ligands. which causes more retention and more negative $\Delta H^{\circ}$ than is expected based on the volume of collapsed ligands. Second, the solutes in this region will cause higher cavity formation enthalpy than the solutes in the bulk nonpolar phase and this effect will result in less negative $\Delta H^{\circ}$. Third. the solutes in this region still feel some functional group-solvent specific interactions, which will give more negative $\Delta H^{\circ}$. The second effect will override the third effect since both effects are caused by the entrapped mobile phase in the stationary phase and the cavity formation effect overrides the solute-solvent interaction effect in the mobile phase. The overall effect can be determined by summing the first effect and the combined effect of the second and the third. The former is greater for all the solutes in the MeCN/water system as shown in Figure 5. while variant trends were observed depending on solute types in the $\mathrm{MeOH} /$ water system. ${ }^{17}$

Preferential uptake of acetonitrile by the Alltima $C_{18}$ phase. Getting far less negative in $\Delta S^{\circ}$ for the Alltima $C_{18}$ phase compared to the squalane-adsorbed $\mathrm{C}_{18}$ phase (Figure 6) seems to be related to the preferential uptake of acetonitrile by the Alltima $C_{18}$ phase. We can see that the $\Delta S^{\circ}$ value of butylbenzene is even positive at the composition of $60 \% \mathrm{MeCN}$. The $\Delta S^{n}$ of butylbenzene will be at least close 
to zero if we consider an experimental error. which means that the solute maintains its freedom when it transfers from the mobile phase to the stationary phase. The $T \Delta S^{\circ}$ of pentylbenzene $(500 \mathrm{~J} / \mathrm{mol})$ or hexylbenzene $(600 \mathrm{~J} / \mathrm{mol})$ is even more positive than that of butylbenzene $(300 \mathrm{~J} / \mathrm{mol})$ as shown in Table 1 . The solute in the Alltima $\mathrm{C}_{18}$ phase will have more freedom than the solute in the squalane-impregnated phase. Nevertheless. it is unlikely that a solute has the same freedom in the stationary phase as that in the mobile phase. The only way to make it rational is assuming preferential uptake of acetonitrile in the effective stationary phase. Butylbenzene (or pentylbenzene or hexylbenzmee) is likely to feel similar or more freedon in acetonitrile/ligand mixture (stationary phase) than in acetonitrile/water mixture (mobile phase). Such gain of solute entropy could be cancelled by the loss of solute entropy owing to the confuned ligand structures in the stationary phase to give virtually the same solute entropy in both of the mobile and stationary phases. Getting more negative in $\Delta S^{\circ}$ with change of $\mathrm{MeCN}$ content from 60 to $80 \%$ in the mobile phase (Figure 6) will be explained in the next section.

Interpretation of the data based on comparison of solvent structure between the MeCN/water and $\mathrm{MeOH} /$ water systems. The different solvent structures between the $\mathrm{MeCN} / \mathrm{water}$ and $\mathrm{MeOH} / \mathrm{water}$ systents and the consequences have been well studied by a few research groups ${ }^{4.19 .31 \cdot .36}$ Their conclusions in such studies seem to be useful to explain our results. too.

Let us rephrase their discussions about the differences in solvent structures between the $\mathrm{MeCN} / \mathrm{water}$ and $\mathrm{MeOH} /$ water mixed solvents. Water is much more sumilar to methanol than it is to acetonitrile in view of polarity and molecular structure. Water-methanol interaction is known to be more favored than water-wvater interaction or methanolmethanol interaction. ${ }^{3.23}$ There are three species in aqueous methanol solution: methanol/water complex, free water. and free methanol. The major species was found the methanol/ water complex when the solution was composed of roughly equal amounts of water and methanol. On the other hand. formation of water-acetonitrile interaction may not be favored compared to maintaining water-water and acetonitrileacetonitrile interactions. ${ }^{4.19 .33-26}$ Therefore water and acetonitrile molecules will tend to form clusters of single components in the mixture although water and acetonitrile are completely mixable at any ratio. Acetonitrile-enriched "microphases" persist in the mobile phase over a wide composition ranges at higher acetonitrile content. ${ }^{+}$In such a situation. the solute is being solvated primarily in "pockets" of acetonitrile molecules. ${ }^{33}$ and the cavity formation effect will be virtually the same for the solvent composition range. The solutesolvent interaction enthalpy will be virtually invariant as well. We can see that variations in $\Delta H^{\circ}$ for the $\mathrm{MeCN} /$ water system are much less than those of the $\mathrm{MeOH} /$ water system in Figures $\mathrm{I}$ and 2 . Getting less negative in $\Delta S^{\circ}$ with decreasing acetonitrile content for the MeCN/water system in contrast to getting more negative with decreasing methanol content for the $\mathrm{MeOH} /$ water system (as shown in Figure 3 and 4), can also be explained by the peculiar behaviour of the $\mathrm{MeCN} /$ water solvent system. Assuming that the solute entropy in the stationary phase is virtually independent of the mobile phase composition. then variation of the solute entropy in the mobile phase govents the variation in $\Delta S^{\mathrm{v}}$. The lower the solute entropy in the mobile phase, the less negative in $\Delta S^{\circ}$. Assuming that the solute in the mobile phase is virtually in the acetonitrile "pockets", then the pocket size will be a critical factor. The smaller the pocket size. the lower the entropy of the solute in it. As the acetonitrile content in the mobile phase decreases. the pocket size will be decreased. too. and so is the solute entropy. Such an effect looks like a hydrophobic interaction, but the mechanism of hydrophobic interaction is entirely different from the process taking place here. The effect is vanished if the acetonitrile content decreases below $50 \%$ as shown in Figures 6 for the squalane impregnated $\mathrm{C}_{18}$ phase.

The real hydrophobic effect caused by water will be found if the acetonitrile content gets even lower (higher water content). Miyabe et $a .^{27}$ observed such effect when the $\mathrm{MeCN}$ composition is less than $20 \%$ for benzene.

The variation trends of $\Delta H^{\mathrm{v}}$ and $\Delta S^{\mathrm{v}}$ with respect to $\mathrm{MeCN}$ composition are not only related to the processes taking place in the mobile phase but also to the processes taking place in the stationary phase since significant differences in the trends between the Altima $C_{18}$ and the squalaneimpregnated $C_{18}$ are observed as shown in Figures 5 and 6 .

The differential solute transfer enthalpy for a pair of nonpolar and polar solutes of the same intrinsic volumes obtained in the MeCN/water system. The differential solute transfer enthalpy $\left(\Delta \Delta H^{\circ}\right)$ between a polar solute and a hypothetical alkylbenzene whose intrinsic volumes are the same, is not exactly equivalent to the solute functional group-solvent specific interaction enthalpy since acetonitrile is entrapped in the effective stationary phase (Alltima $C_{18}$ ). We derived the functional group-MeCN/water specific interaction enthalpies despite the low reliability of their absolute values and plotted them in Figure 7. The results are at least

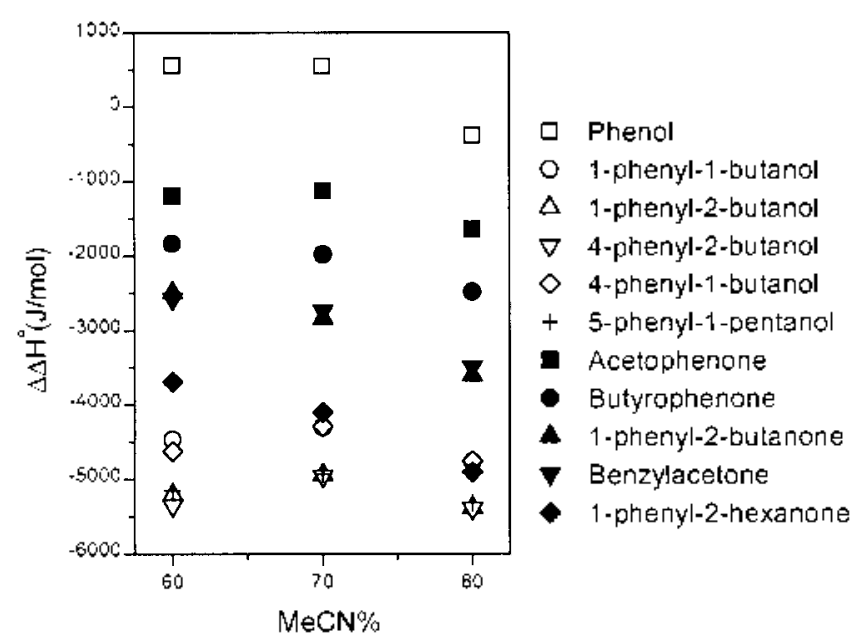

Figure 7. The funcional group-MeCN/water specific interaction enthalpies monitored by the Alltima $\mathrm{C}_{18}$ stationary phase. 
in agreement with chemical senses. The absolute magnitudes of the data are subject to a high error, but the signs and order of magnitudes are consistent to the common sense of chemistry. The hydroxyl group-MeCN/water interactions are in general stronger than the carbonyl group-MeCN/water interactions as we discussed before. There exist clear discrepancies antong positional isomers and the variation in the functional group-solvent interaction with respect to mobile phase composition for ketones is nuch greater than that for alcohols as we observed in the previous study. ${ }^{17}$ The general trends of positional effect are also similar to those observed in the previous study ${ }^{17}$ although reversion of order is found in one or two cases probably owing to the different solvent behaviors in the MeCN/water system from those in the $\mathrm{MeOH} /$ water sy stent.

An interesting thing is the $\Delta H^{0}$ values of phenol. They are even positive or at least close to zero if uncertainty is considered. Its meaning is that phenol feels sinilar or stronger functional group-phase interaction in the stationary phase than in the mobile phase. The unusual aspect of phenol can also be found in the $\Delta S^{\circ}$ data (Table 1). Phenol has abnormally more negative $(-19 \mathrm{~J} / \mathrm{mol} . \mathrm{K}$ at $70 \% \mathrm{MeCN})$ values than other solutes. for example. bezene $(-7 \mathrm{~J} / \mathrm{mol} \mathrm{K})$ or toluene $(-6 \mathrm{~J} / \mathrm{mol} . \mathrm{K})$. Residual silanol group effect seems to be related to such a phenomenon. The Alltima $C_{18}$ stationary phase is known to be end-capped. Nevertheless. there should be still some residual silanol groups which are sterically hindered and are hard for large solutes to approach but are accessible by a sntall solute such as phenol. Capture of phenol by the silanol group will be accompanied by occurrence of a strong functional group-stationary phase interaction and a large decrease of solute entropy in the stationary phase. This explanation is based on the hypothesis that the residual silanol groups are well hidden to large solutes but are exposed to small molecules such as phenol.

\section{Conclusion}

We have measured solute transfer enthalpies and entropies from the acetonitrile/water mobile phase to the Alltima $C_{18}$ stationary phase and critically analyzed and compared the data with those previously obtained in the methanol/water mobile phase. The hydroxyl group-acetonitrile/water interaction has proven to be stronger than the carbonyl groupacetonitrile/water interaction while the carbonyl groupmethanol/water interaction was stronger than the hydroxyl group-nethanol/water interaction. There are clear discrepancies in functional group-solvent interaction among positional isomers. Hydrogen bond interaction is the major factor in specific interactions and dipole-dipole interaction will contribute a little. while steric effect becomes important when positional isomers are comparatively examined. In addition, mobile phase composition is also an important factor in the specific interaction between the solute functional group and the mobile phase. There existed clear differences in trends of variation of $\Delta H^{\circ}$ and $\Delta S^{\circ}$ with respect to mobile phase composition between the methanol/water and acetonitrile/water systems. The formation of acetonitrile pockets described in the literature was useful to explain such results.

Acknowledgment. This work was the result of the project of Center for Advanced Bioseparation Technology at Inha University supported by Korea Science and Engineering Foundation.

\section{References}

1. Grushka. E.: Colin, H. Guichon, G. Anal Chem. 1982, 248. 325.

2. Issaq. H. T.: Taroniec. M. J. Liq. Chrontatogr. 1989. 12. 2067.

3. Cole. L. A.: Dorsey. T. G. Anal Chent 1992. 64. 1317.

4. Alvarez-Zepeda. A.: Barman. B. N.: Martire. D. E. Anal. Chem. 1992. 64, 1978 .

5. Tchapla, A.: Heron, S.; Colin. H.; Guichon. G. Anal. Chem 1988. 60. 1443 .

6. Yamamoto. F. M.: Rokushika. S.: Hatano. H. J. Chomatogr: Sci. 1989. 27. 704

7. Sander. L. C.: Field. L. R. Anal Chent 1980. 52.2009.

8. Bell. C. M.: Sander, L. C.: Wide, S. A. J. Chromatogr A 1997. 757.29

9. MoGuffin, V. L. Chen, S. I. Chromatogr A 1997. 762, 35

10. Miyabe. K.: Suzuki. M $A H C h E J$. 1995. $H 1.548$.

11. Miyabe. K.: Takeuchi. S. Anal Chen 1997. 69. 2567.

12. Guillaume. Y.: Guinchard. C. J. Liq. Chrontatogr 1994. 17. 2807.

13. Lee. C. S.; Cheong, W. J. J. Liq. Chom \& Rel Techol 1999, 22. 253 .

14. Lee, C. S.: Cheong. W. J. J. Chromatogr A 1999. 848.9.

15. Cheong. W. J.: Kim. C. Y.: Koo. Y. M. Bull. Korean Chem. Soc. 2000. 21. 105

16. Cheong. W. J.: Kiml. C. Y. Bull Korem Chent. Soc. 2000. 21.351.

17. Cheong. W. J.: Keum, Y. I. J. Chromatog: A 2001, 910. 195.

18. Guillaume. Y. C. Guinchard C. Chromatographia 1995. 11.84.

19. Guillaume, Y. C.: Guinchard C. Anal Chem. 1996, 68. 2869.

20. Guillaume. Y. C.: Cavalli. E. T.: Peyrin. E.: Gunichard. C. J. Liq. Chron. \& Rel. Technol 1997.20.1741.

21. Katz. E. D.: Ogan. K.: Scott. R. P. W. J. Chromatogr: 1986. 352. 67

22. Guillaume. Y. C. Guinchard, C. Anal. Chem. 1998, 70.608.

23. Stalcup. A.; Martire. D. E.; Wise. S. A. J. Chromatogr. 1988, 412. 1 .

24. Lowenschuss. A.: Yellin. N. Spectrochin. Acta 1975. 3LA. 207.

25. Rowlen. K. L.: Harris. T. M. Anal. Chent 1991. 63.964.

26. Stokes. R. H. J. Chem. Themodm. 1987. 19.977.

27. Mivabe. K; Takeuchi, S. Anal. Chem 1997, 69, 2567. 